\title{
Influence of agitation leaching conditions to the behavior of gold in solution
}

\author{
Konstantin Prokhorov ${ }^{1 *}$ \\ ${ }^{1}$ Mining Institute of Far eastern branch of Russian Academy of Sciences, Khabarovsk, Russia
}

\begin{abstract}
Deposition of gold ions in the process of agitation with a chloride-hypochlorite solution with $8.15 \mathrm{~g} / 1$ active chlorine concentration in the model material was studied. Fresh chlorite-hypochlorite solution was used in the study. The effect of the initial $\mathrm{pH}$ of the medium on the dynamics of gold deposition is considered. It was found that up to $56 \%$ of gold precipitates in alkaline medium. Precipitation is not observed at $\mathrm{pH}<6$. It is established that the ore under investigation has buffer properties and stabilizes the $\mathrm{pH}$ of the medium to weak-acid $(\mathrm{pH}=5.5-6)$.
\end{abstract}

\section{Introduction}

Due to the growing environmental concern of the use of cyanide for gold processing, interest on the use of non-cyanide lixiviants especially with halides has been renewed recently. Despite the fact that cyanide is used commercially for gold extraction, studies are being conducted on alternative non-toxic leaching agents. Based on the works $[1,2,3]$, the suitability of chloride systems for gold leaching from ores was determined. In the study [4], the authors found that the leaching of gold from the ore should be properly controlled to achieve a high rate of gold recovery and dissolution. In this case, sodium hypochlorite provides a higher reaction rate with gold compared to the same calcium hypochlorite.

In [5] was noted that hydrochloric acid and $\mathrm{NaCl}$ and $\mathrm{NaOCl}$ salts solutions significantly increase $\mathrm{Cl}_{2}\left(\mathrm{Cl}_{3}^{-}\right)$solubility. In an aqueous $\mathrm{HOCl}-\mathrm{NaOCl}-\mathrm{NaCl}-\mathrm{HCl}$ solution, when $\mathrm{HOCl}$ is consumed, its concentration is recovered by acidifying (as long as the solution keeps containing $\mathrm{NaOCl}$ )

$$
\mathrm{NaClO}+\mathrm{HCl}<-->\mathrm{HClO}+\mathrm{NaCl}
$$

By contrast, in alkaline solutions, hypochlorites undergo decomposition, depending on $\mathrm{pH}$, by the equation

$$
2 \mathrm{OCl}^{-} \rightarrow 2 \mathrm{Cl}^{-}+\mathrm{O}_{2}
$$

As a result, the authors note that chloride-hypochlorite solutions can be used to extract gold from gold-bearing industrial raw materials (ores, concentrates). The oxidation of gold by films of solid reaction products can be prevented by conducting the process at a sufficiently low $\mathrm{pH}$.

\footnotetext{
*Corresponding author: kostyan1986_ne@mail.ru
} 
All studies of the gold dissolution using oxidizers or complexing agents based on halides indicate the importance of controlling the $\mathrm{pH}$ of the solution to stabilize the gold complex. Otherwise, gold can be reprecipitated already after its dissolution from ore [6]. And this fact, in our opinion, is the main problem of the gold extraction process by chloride systems leaching.

\section{Experimental}

This study is an investigation of the behavior of dissolved gold in the process of agitation leaching from a model material based on the base ore of the Malmyzh deposit with a fresh chloride-hypochlorite solution. Previous studies have shown that in the process of gold extraction with a hypochlorite solution in close to neutral medium, the gold is reprecipitated from solution to the ore. Thus, gold is extracted from the ore, but does not remain in solution.

To studying the process of gold reprecipitation in pregnant solutions depending on the $\mathrm{pH}$ of the medium a model material was used. A fixed amount of a solution of gold ions of known concentration was added to the base ore of the Malmyzh deposit. Thus, reproducible initial conditions of the initial concentration of gold in the samples were created. For each experiment, a fresh chloride-hypochlorite solution of known composition and $\mathrm{pH}$ was taken. The preparation of the chloride-hypochlorite solution was carried out by $\mathrm{NaCl}$ electrolysis followed by the addition of hydrochloric acid. The pulp was pre-treated with ultrasound and leached in agitation mode.

At the first stage, the extraction was simulated using a solution of hypochlorite, previously adding gold solutions to the sample. In the process of leaching, the solid to liquid ratio was 1:4. This ratio was chosen to reduce the heating of the pulp during sonication. With a smaller of solid to liquid ratio, during the cavitation process, the pulp is heated up, the liquid is evaporated, chlorite-hypochlorite solution is degassed, and, as noted [6], the decomposition of dissolved gold is more pronounced at higher temperatures. Ultrasonic treatment was performed for 10 minutes. Then the sample has been placed in agitator for 4 hours. After the interaction of the chloride-hypochlorite solution with the model material, an aliquot was taken for analysis. A blank experience was also conducted to verify the absence of gold extraction from the base ore. After conducting a blank experiment, an aliquot of the liquid phase was taken from the pulp for analysis. The remaining volume of the liquid phase after the blank experiment was divided into portions and a solution of gold ions was added for comparison.

The second stage was the study of the behavior of gold ions as a function of the $\mathrm{pH}$ of the medium. Equal weighed portions were mixed with a chloride-hypochlorite solution having a different initial $\mathrm{pH}(3,5$, and 9). In a defined time intervals, $30 \mathrm{ml}$ of the slurry was sampled and filtered. Gold content of the clarified solutions was analyzed by the atomic absorption method on AA-7000 (Shimadzu). According to the data on the amount of gold in solution at a certain time interval, curves were obtained.

\section{Material}

For the first stage of the study, a solution of gold ions was added to the samples of the test sample (base ore), simulating $0.8 \mathrm{~g} / \mathrm{t}$ and $2 \mathrm{~g} / \mathrm{t}$ gold in the ore. In parallel, a blank experiment was conducted without the addition of gold ions, adding it after leaching. Agitation was conducted with a fresh chloride-hypochlorite solution with an active chlorine $8.15 \mathrm{~g} / \mathrm{l}$ concentration and 9.37 initial $\mathrm{pH}$. The solution was prepared by electrolysis of 20 $\mathrm{g} / \mathrm{l}$ sodium chloride solution by a Saner 3-50 unit. 
For the second stage of the study, a solution of gold ions was added to the samples of the model material, simulating $2 \mathrm{~g} / \mathrm{t}$ gold in the ore. The extraction was carried out with the same chloride-hypochlorite solution with $8.15 \mathrm{~g} / \mathrm{l}$ active chlorine concentration and 3, 5 and 9 initial $\mathrm{pH}$.

\section{Results}

\subsection{Investigation of gold deposition in the process of agitation, depending on the initial conditions for the concentration of gold ions.}

The prepared pulp with the model material was sonicated for 10 minutes, and then the process was carried out in agitation mode for four hours.

The conditions and results of the experiment to determine the reprecipitation of gold ions during the agitation process with hypochlorite solution are shown in Table $1.100 \%$ gold extraction equals the added amount of gold ions to the base ore.

Table 1. Conditions and results of modeling experiment

\begin{tabular}{|c|c|c|c|}
\hline № & Composition of pulp & Gold extraction, $\%$ & Final $\mathrm{pH}$ \\
\hline 1 & Base ore $+\mathrm{Au} 0,8 \mathrm{~g} / \mathrm{t}$ & 89,59 & 8,06 \\
\hline 2 & Base ore $+\mathrm{Au} 2 \mathrm{~g} / \mathrm{t}$ & 62,45 & 7,52 \\
\hline 3 & Blank experiment & 0 & 8,37 \\
\hline 4 & Blank experiment $+\mathrm{Au} 0,8 \mathrm{~g} / \mathrm{t}$ & 100,0 & \\
\hline 5 & Blank experiment $+\mathrm{Au} 2 \mathrm{~g} / \mathrm{t}$ & 100,0 & \\
\hline
\end{tabular}

Data given in table 1 demonstrate that gold precipitates (up to $37.55 \%$ ) in the agitation process with chloride-hypochlorite solution (No. 1, 2). In this case, the amount of precipitated gold is directly depended on its initial amount in solution. Gold added after the process of agitation with blank ore was completely extracted to the pregnant solution $(100 \%$ extraction, No. 4,5$)$. The final $\mathrm{pH}$ of the medium was neutral or slightly alkaline. Therefore, the next step was to investigate the effect of the $\mathrm{pH}$ of the medium on the process of reprecipitation of gold by shortening the sampling intervals for analysis.

\subsection{Investigation of the dependence of the gold ions deposition on the $\mathrm{pH}$ of the medium.}

The prepared pulp with the model material was sonicated for 10 minutes, then the process was carried out in agitational mode for four hours. Aliquots were taken after ultrasonic treatment, and then every hour during the leaching process. The results of gold content in aliquots for different initial $\mathrm{pH}$ of the medium are shown in Figure 1.

At the initial stage, the quantity of added gold ions is $100 \%$ gold extraction. Further, during the agitation of pulps with an initial $\mathrm{pH}=9$, more than half of the added gold ions are precipitated and the extraction drops to $44 \%$. In the experiment using a chloridehypochlorite solution with 5 and 3 initial $\mathrm{pH}$, gold deposition is not observed, the extraction is about $100 \%$. 


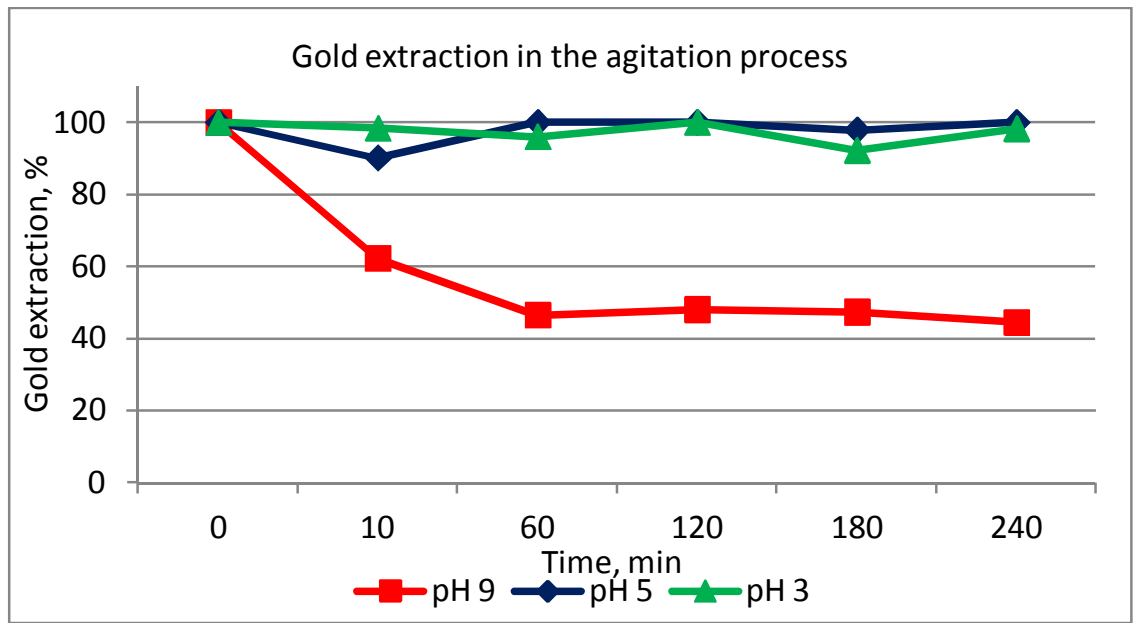

Fig. 1. Dynamics of the reprecipitation of gold ions from the solution as a function of the initial $\mathrm{pH}$ of the solution.

During the experiment, $\mathrm{pH}$ of the medium was also observed. The $\mathrm{pH}$ dynamics is shown in Figure 2. In the experiment with a chloride-hypochlorite solution with the initial $\mathrm{pH}=9$ during the agitation process, the $\mathrm{pH}$ drops to slightly alkaline medium, and at the last hour to neutral one. In experiments with a solution of hypochlorite with an initial $\mathrm{pH}$ of 5 and 3 during the agitation, the $\mathrm{pH}$ of the pulp has rise to slightly acidic (about 6).

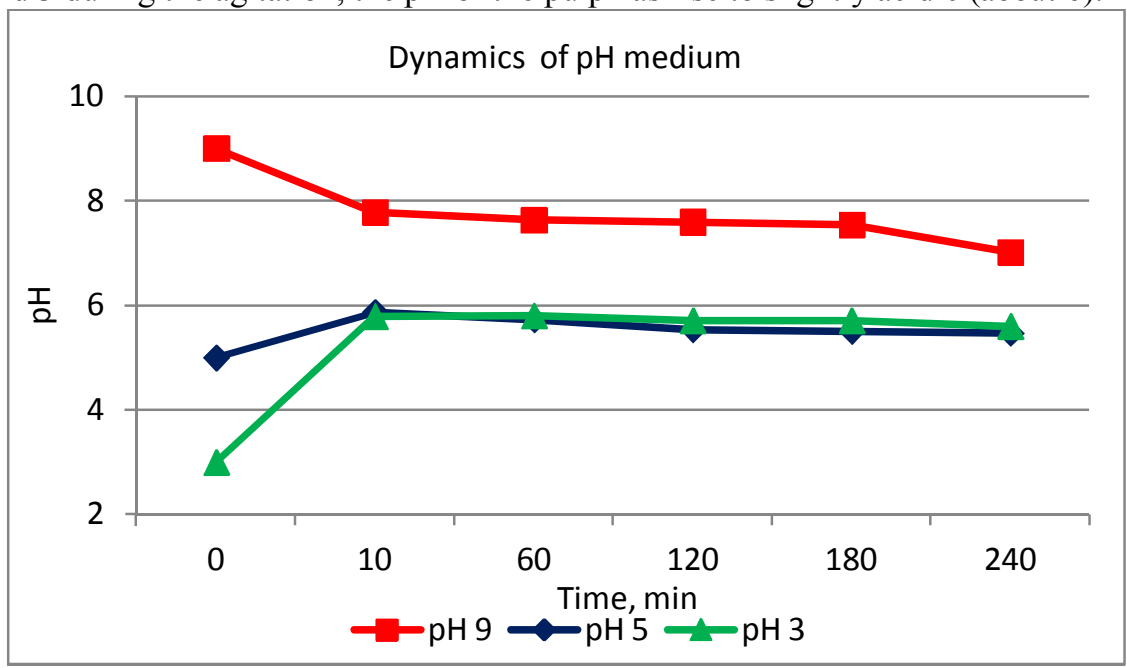

Fig. 2. Dynamics $\mathrm{pH}$ of the hypochlorite solution during the pulp agitation process.

The results of this research showed that the ore has buffer properties and tends to stabilize the $\mathrm{pH}$ level closer to the weakly acidic $(\mathrm{pH}=5.5-6)$. At $\mathrm{pH}$ below 6 , gold does not precipitate in the model material, and gold extraction increases. Acidic medium $(\mathrm{pH}<6)$ prevents gold precipitation from solution to the solid phase.

\section{Conclusions}

The process of reprecipitation of gold ions as a function of the $\mathrm{pH}$ of the leaching medium has been studied. The results of the study showed that at the initial alkaline $\mathrm{pH}$ of the 
medium, more than half of the gold ions (up to 56\%) precipitated from the solution during the first hour of treatment. In this case, the amount of precipitated gold depends on its initial content in solution. When the process is carried out in acid medium, no precipitation of gold from the solution is observed. It is noted that the pulp has buffer properties and stabilizes $\mathrm{pH}$ of the medium to weakly acid $(\mathrm{pH}=5.5-6)$. In the process of research of oxidized ore of the Malmyzh deposit it was concluded that it is necessary to carry out the gold leaching processes at 6-5 $\mathrm{pH}$ to prevent the precipitation of one.

The author is grateful to the staff of MI FEB RAS, who took direct part in carrying out experimental studies: A.G. Sekisov, T.G. Konareva, A.V. Rasskazova. Research was supported by Far Eastern branch of Russian Academy of Sciences project (18-2-015 "Gold and copper and porphyritic mineralization of the Far East: indicators of geodynamic situations, ore-bearing magmatism and mineralogical-geochemical features of ore and magmatic systems in connection with the solution of problems of the forecast, prospecting, assessment and technologies of development of fields of this type"

\section{References}

1. M. G. Aylmore. Developments in Mineral Processing. 15. 501-539. (2005).

2. G.V.K. Puvvada, D.S.R. Murthy. Hydrometallurgy. 58. 185-191. (2000).

3. T.A. Harlamova, A.F. Alaferdov, V.M. Bahir. Gornyiy informatsionnoanaliticheskiy byulleten (nauchno-tehnicheskiy zhurnal). 3. 108 - 117. (2015).

4. M. Baghalha. Int. J. Miner. Process., 82. 1166-1171. (2007)

5. L. F. Kozin, V. A. Prokopenko and A. K. Bogdanova. Protection of metals, 41 (1). 22-29. (2005).

6. Kwang Soo Nam, Byoung Hi Jung Jeon Woong An Tae Jun Ha. Int. J. Miner. Process. 86. 131-140. (2008). 